\title{
Feedback loops and oscillations in modular hierarchical brain networks: the topological origin of brain rhythms
}

\author{
Marcus Kaiser ${ }^{1,2}$
} Address: ${ }^{1}$ School of Computing Science, Claremont Tower, Newcastle University, Newcastle-upon-Tyne, UK and ${ }^{2}$ Institute of Neuroscience,
Framlington Place, Newcastle University, Newcastle-upon-Tyne, UK

Email: Marcus Kaiser - m.kaiser@ncl.ac.uk

from Eighteenth Annual Computational Neuroscience Meeting: CNS*2009

Berlin, Germany. 18-23 July 2009

Published: 13 July 2009

BMC Neuroscience 2009, I0(Suppl I):P28| doi:10.1 |86/|47|-2202-I0-SI-P28|

This abstract is available from: http://www.biomedcentral.com//47I-2202//0/SI/P28I

(c) 2009 Kaiser; licensee BioMed Central Ltd.

\section{Introduction}

Coupled systems often show oscillatory rhythms. Whereas these oscillations have been studied for couplings of a few nodes, here we show how the topology of large-scale networks influences oscillations. Oscillations or rhythms have been observed in brain networks, measured by the electro-encephalogram (EEG). Starting from 1929, distinct frequency bands (e.g. alpha, beta, or gamma) were identified. These bands are the same for different species [1]. Similar frequency bands are also observed across different levels of neural organizationfrom EEG signals to local field potentials. Studying hierarchical modular neural networks [2], we find distinct frequency peaks of neural rhythms, similar to experimentally observed rhythms in various species, from rats to humans.

\section{Results}

We define the oscillation interval $T$ that a signal propagates in a feedback loop as the path length of the loop $L$ times the average delay of transmission $D$ over a single connection. The oscillation frequency is thus $F=1 / T=1$ / $(L D)$. We generated a hierarchical and modular neuronal network based on known cortical anatomy [3]. Peaks in the frequency power distribution arose both at the global and the local level (Figures 1,2,3). In addition, many ratios were irrational, therefore leading to quasi-periodic patterns with minimum interference between different oscillation frequencies.

\section{Conclusion}

Hierarchical networks based on anatomical connectivity [2] can generate frequency distributions with (a) distinct

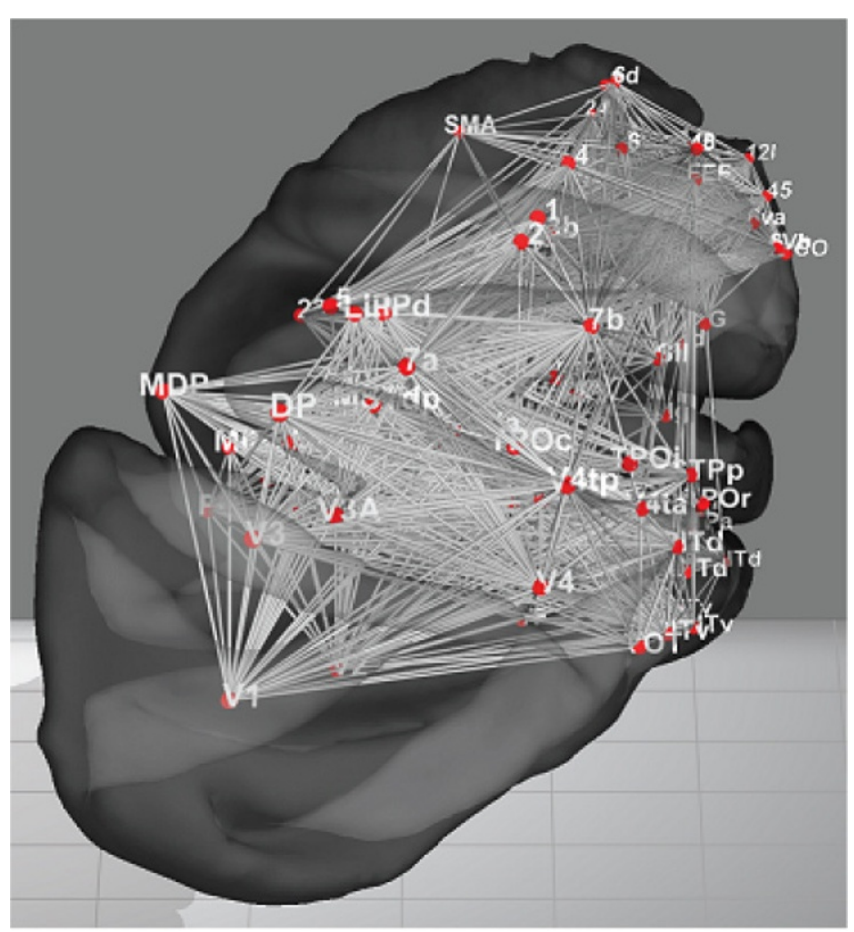

Figure I

Mammalian cortical fiber-tract network. 


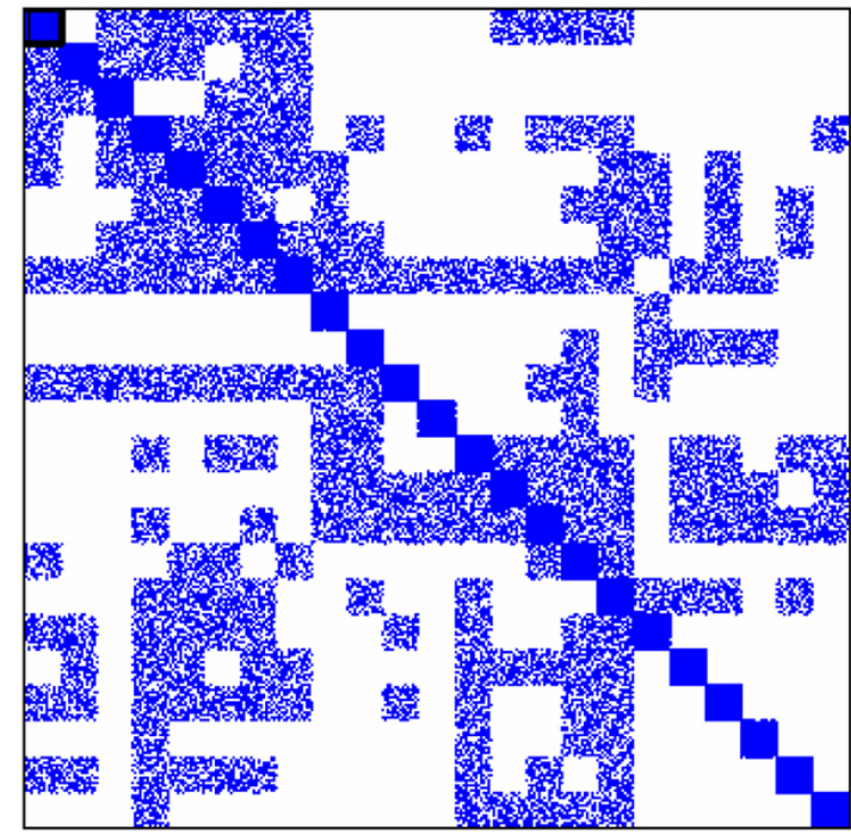

Figure 2

Hierarchical network of cortical regions with modular structure within regions (not shown).

frequency peaks, (b) peaks in similar ranges as known from electrophysiology, and (c) with ratios between peaks that are close to the irrational numbers $\phi$ or $e$ which are beneficial for low signal interference.

\section{Acknowledgements}

We thank EPSRC (EP/E00233I/I) and the Royal Society (RG/2006/R2) for financial support.

\section{References}

I. Buzsaki G: Rhythms of the Brain Oxford University Press; 2006.

2. Kaiser M, Görner M, Hilgetag CC: Functional criticality in clustered networks without inhibition. New J Phys 2007, 9: I I0.

3. Sporns O, Chialvo D, Kaiser M, Hilgetag CC: Organization, development and function of complex brain networks. Trends Cogn Sci $2004,8: 418-425$

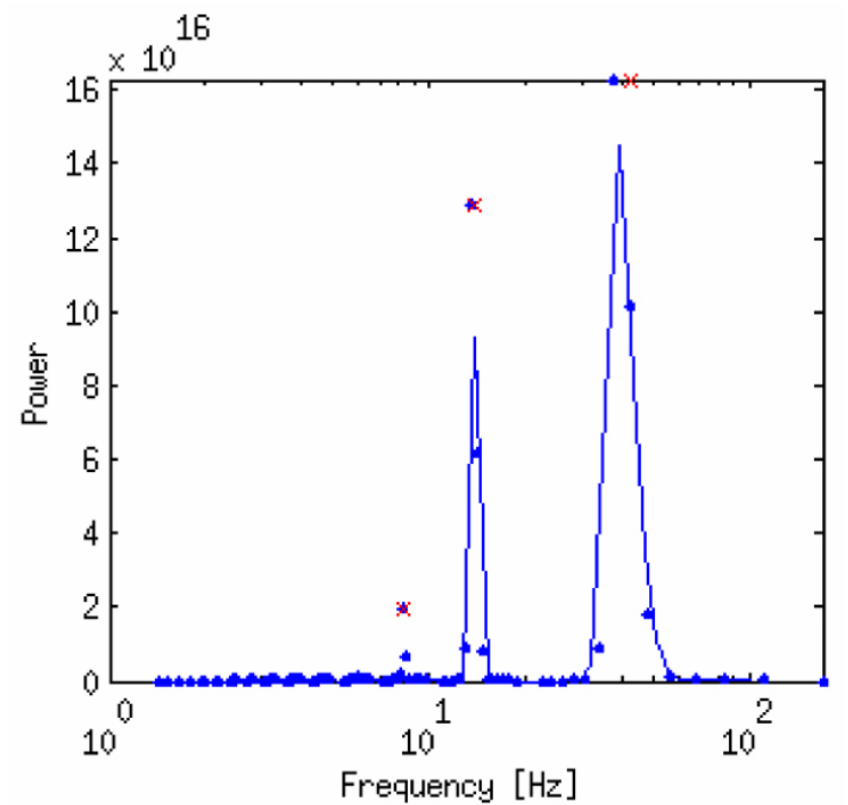

Figure 3

Frequency peaks due to feedback loops in the network.
Publish with Biomed Central and every scientist can read your work free of charge

"BioMed Central will be the most significant development for disseminating the results of biomedical research in our lifetime. "

Sir Paul Nurse, Cancer Research UK

Your research papers will be:

- available free of charge to the entire biomedical community

- peer reviewed and published immediately upon acceptance

- cited in PubMed and archived on PubMed Central

- yours - you keep the copyright

Submit your manuscript here:

http://www.biomedcentral.com/info/publishing_adv.asp
BioMedcentral 